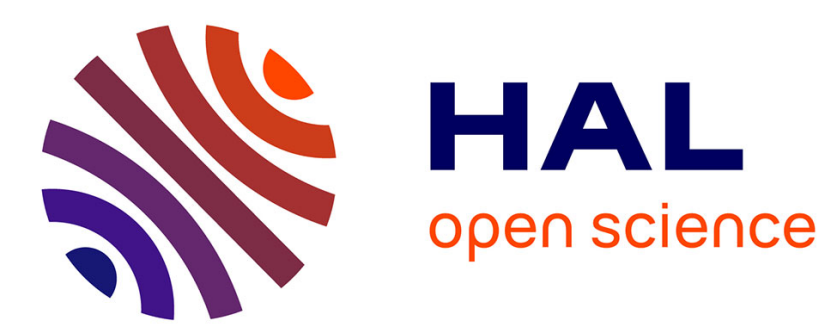

\title{
Portable XRF and wet materials: application to dredged contaminated sediments from waterways
}

\author{
Bruno Lemiere, Valérie Laperche, Laurence Haouche, Pascal Auger
}

\section{To cite this version:}

Bruno Lemiere, Valérie Laperche, Laurence Haouche, Pascal Auger. Portable XRF and wet materials: application to dredged contaminated sediments from waterways. Geochemistry: Exploration, Environment, Analysis, 2014, 14, pp.257-264. 10.1144/geochem2012-179 . hal-00872341

\section{HAL Id: hal-00872341 https: / hal-brgm.archives-ouvertes.fr/hal-00872341}

Submitted on 5 Sep 2014

HAL is a multi-disciplinary open access archive for the deposit and dissemination of scientific research documents, whether they are published or not. The documents may come from teaching and research institutions in France or abroad, or from public or private research centers.
L'archive ouverte pluridisciplinaire HAL, est destinée au dépôt et à la diffusion de documents scientifiques de niveau recherche, publiés ou non, émanant des établissements d'enseignement et de recherche français ou étrangers, des laboratoires publics ou privés. 
1 Portable XRF and wet materials: application to dredged contaminated sediments from waterways

${ }^{1}$ BRGM, Environment and Process Division, BP 36009, 45060, Orleans, France

${ }^{2}$ ISSeP, Zoning A. Schweitzer - Rue de la Platinerie - B-7340 Colfontaine, Belgium, I.haouche@issep.be

${ }^{3}$ Corresponding author (email: b.lemiere@brgm.fr)

8 ABSTRACT: The sustainable management of dredged waterway sediments requires on-site determination 9 of the main pollutants to facilitate their safe reuse or treatment. Portable X-ray fluorescence (pXRF) is

commonly used for similar applications with contaminated soil, but the high water content of dredged sediments precludes any application of standard methods. Measurements for $\mathrm{Pb}, \mathrm{Zn}, \mathrm{Cu}$ and $\mathrm{As}$ were performed on-site on raw wet sediments with 50 to $70 \%$ water contents during dredging or mapping operations. These results, although two or three times lower than laboratory analyses on the same samples, were found to be related to absolute concentrations closely enough to rank samples. In order to investigate further the feasibility of field analyses on wet sediments, partial dehydration methods were tested. The most efficient technique is based on a hand press. It is simple and quick enough to be used on dredging boats during operations and produces sample pellets with 30 to $50 \%$ water contents. The relationship between pXRF measurements on these pellets and laboratory analyses was found to be sufficiently linear to calculate estimated concentrations. Potential differences were found to be less than $20 \%$ for $\mathrm{Pb}$ and $\mathrm{Zn}$. Higher differences for $\mathrm{Cu}$ were due to very low concentrations, within twice the limit of detection (LOD). Some limitations were observed. The water content in pellets is variable depending on the sediment type or matrix. The correction factors vary between the measured elements and they may also vary with matrix chemistry. However, $\mathrm{Pb}-\mathrm{Zn}-\mathrm{Cu}-\mathrm{As}$ concentrations were ranked and evaluated accurately and the geochemical signatures of the samples were preserved.

We demonstrated that, with a simple partial dehydration procedure, pXRF measurements can be reliably related closely enough to absolute concentrations to make field decisions for sediment management. Since the approximately linear relationships between measurements on semi-wet samples and laboratory analyses are matrix- and site-dependent, they must be recognised before using $\mathrm{pXRF}$ on wet samples for decision making.

KEYWORDS: portable XRF, water, moisture, contaminated sediments, waterways, dredging 
Environmental applications of portable X-ray fluorescence spectrometry (pXRF) were developed for soil as early as the 1990s (Shefsky 1995). These applications have been validated by the development of the EPA 6200 standard method (US-EPA 2007). Matrix similarity with waterway or harbour sediments suggested the scope of pXRF could be extended to these measurements (Kirtay et al. 1998; Plater et al. 1999). However, this development has faced difficulties due to a much broader range of water contents in sediments. It was soon demonstrated that water contents above $20 \%$ in soil or sediment could be a major source of error on absolute results (US-EPA 2007), but neither the type of error nor its relationship with water contents were investigated. It was only recommended to dry the samples before measurements.

Some applications of pXRF are based on the ability to provide immediate measurements, without waiting for drying. Examples of such applications occur during contaminated site remediation operations. The term 'measurement' is used deliberately instead of 'analysis', since absolute accuracy is not mandatory for decision-making. Sensitivity and reproducibility are more essential for most decisions. The incorporation of such measurements in the data-set supporting a decision is possible, provided that the level of uncertainty is properly quantified. This was successfully implemented in the Dynamic Sampling Plans (Robbat 1997), ASAP (US-DOE 2001) and Triad (Crumbling 2001) approaches to decision-making.

Sediments accumulate over time in canals and other waterways. They comprise eroded soil, industrial or urban muds and wastewater-derived solids. Periodic dredging is required to maintain navigability. Waterway sediments are often contaminated by a wide range of potentially toxic substances, a legacy of the industrial history and urbanisation (Martin 2004; Laboudigue et al. 2011). Among these substances, heavy metals and metalloids (atomic mass $>39$ ) can be determined by pXRF. This method can operate in rough field conditions and with basic training of local staff without compromising the quality of results (Higueras et al. 2012).

Sediment dredging and management may benefit from immediately available measurements in several ways (Lemière et al. 2012a, b): during sampling operations aimed at the preliminary characterisation of a canal section to be dredged; during dredging operations, at the dredging site or on the boat; after dredging operations, while entering the treatment facility; and after dredging operations, while unloading at the sediment reuse site. In all these situations, the sediment samples have water contents typically between 30 and 70\% (Dalmacija et al. 2006; unpublished data by VNF (French Inland Waterways) and SPW (Public Service of Wallonia)).

However, it may be impractical to dry samples on-site. Measuring the water content on-site is not an easy alternative either: sediments are too fluid for humidity sensors based on pin electrodes or too absorbent for infrared techniques due to their high organic matter content.

The purpose of the present study was to: (1) investigate the relationship between water content and measurement reliability; (2) identify practical and reproducible field techniques for drying sediment samples to standard water content, and; (3) establish a viable compromise between measurement quality, handling time and practicality.

The robustness, low cost and performance characteristics of pXRF spectrometers enable easier, more flexible operation and more widespread availability in dredging operations than any other instrument. 


\section{MATERIALS AND METHODS}

\section{Sample types and preparation}

On-site analysis of waterway sediments by pXRF was performed at various occasions during 'GeDSeT', a research project on sediment management (Laboudigue et al. 2011; Lemière et al. 2012b). Portable XRF was therefore used on-site for pollutant characterisation before dredging, during dredging operations, at sediment disposal sites on land and during sediment remediation pilot tests.

The evaluation of the suitability of pXRF for waterway sediments was one of the objectives of the project and $\mathrm{pXRF}$ testing was performed routinely alongside most project activities. As a consequence, the sample sets studied here are not homogeneous and the results discussed in the present paper were obtained through the comparative analysis of tests carried out during campaigns in several different locations and situations, rather than through a straightforward experimental plan.

Sediment samples for pollutant characterisation before dredging were collected using a hand auger (Figure 1). They were processed, partly dehydrated and analysed on-board the boat used by SPW (Public Service of Wallonia). Dehydration was performed by manual hand-pressing in tissue paper (2010 campaign) (Figure 2) or using a filter press device (2011 campaign) (Figure 3a and b). The filter press was developed by the pXRF manufacturer to deal with wet samples or sludge. Pressure is gradually increased by hand in order to allow a progressive release of water. It can be operated under any field conditions, without electricity, and allows short delays (5 to $10 \mathrm{~min}$ ) between sampling and analysis. For these reasons, it was preferred to Büchner filtration and to induction heating.

Sediment samples were also tested during pilot tests for remediation. They were partly dehydrated and analysed on-site during pilot tests for sediment processing, including grain size separation and floatation tests (Bréquel et al. 2012). Dehydration was then performed by manual hand-pressing in tissue paper.

Samples collected on-site were further tested in the laboratory, both as raw wet samples and as partly dehydrated samples. This made it possible to compare field measurements on partly dehydrated samples with oven-dried samples and to quantify water losses.

For all these sample types and situations, the preparation method was the best one available at the time of the test. Most of the situations were short-lived and it was not possible to return later and test new preparation methods. This meant it was not possible to carry out a comprehensive comparison of methods, but instead reflects the continuous evolution of methods.

\section{Analysis}

pXRF parameters All pXRF measurements were performed using two Niton analysers from Thermo Scientific: the XLt999KWY and XL3t800 models. The energy dispersive XLt999KWY is equipped with a $35 \mathrm{kV}$ X-ray tube (max. $35 \mathrm{kV}, 10 \mu \mathrm{A}, 1.7 \mathrm{~W})$ with an Ag anode target excitation source and a Si-PIN diode detector. The analysed spot has an average diameter of $20 \mathrm{~mm}$. The XL3t800 is equipped with a $50 \mathrm{kV} X-$ ray tube (max. $50 \mathrm{kV}, 100 \mu \mathrm{A}, 2 \mathrm{~W}$ ) with an $\mathrm{Ag}$ anode target excitation source and a Large Drift Detector (LDD). The analysed spot has an average diameter of $8 \mathrm{~mm}$. As part of the standard set-up routine, the analyser was initially calibrated using silver and tungsten shielding on the inside of the shutter and the source count time for the analysis was fixed either at 30 seconds on the main filter (for quick $\mathrm{Pb}, \mathrm{Zn}$ and $\mathrm{Cu}$ pollution identification on the canal) or at 120 seconds using the 3 filters of the pXRF unit (for a total analysis on-site or in the laboratory). All analyses were performed using the soil mode calibration provided by the manufacturer. The actual limit of detection (LOD) for $\mathrm{Pb}, \mathrm{Zn}$ and $\mathrm{Cu}$ is matrix-dependent. An estimate of the LOD is evaluated by the instrument during measurements; it depends also upon detector 
performance. In a soil-type matrix, it was found to be c. 18, 48 and $80 \mathrm{mg} / \mathrm{kg}$ with the XLt999KWY and 8 , 13 and $20 \mathrm{mg} / \mathrm{kg}$ with the XL3t800, respectively, for $\mathrm{Pb}, \mathrm{Zn}$ and $\mathrm{Cu}$.

Laboratory analyses Analyses were carried out by the laboratories of CTP (Tournai, Belgium) and ISSeP (Colfontaine, Belgium). In the laboratory, all samples were homogenized and then split. One sub-sample was dried at $40^{\circ} \mathrm{C}$ in an oven and milled $(<80 \mu \mathrm{m})$. Moisture was determined by weight loss in a separate sub-sample by drying at $105^{\circ} \mathrm{C}$ overnight. Two options for digestion were available, depending on the purpose of the analysis.

In the ISSeP laboratories, all samples were digested in aqua regia ( $8 \mathrm{ml}$ for $0.5 \mathrm{~g}$ ) for 45 minutes. For the analyses carried out by the CTP laboratories, a $1 \mathrm{~g}$ fraction was digested at $185^{\circ} \mathrm{C}$ in a digestion bomb with concentrated $\mathrm{HNO}_{3}$ and $\mathrm{HF}$. The samples were oven-dried at $105^{\circ} \mathrm{C}$ for $8 \mathrm{~h}$ to ensure complete evaporation of HF. Complete dryness was obtained by heating on a hot-plate up to $120^{\circ} \mathrm{C}$. The dried residue was then dissolved in $\mathrm{HNO}_{3}$ for $c .12 \mathrm{~h}$ on a hot plate at $120^{\circ} \mathrm{C}$ and dried again on a hotplate at $120^{\circ} \mathrm{C}$. The dried residue was then dissolved again in $\mathrm{HNO}_{3}$. In both laboratories, measurements were performed using ICP-AES.

HF digestion can be considered as near-total, while aqua regia digestion is a partial method. However, in waterway sediments, most carrier phases for the elements of interest in this paper are effectively dissolved by aqua regia.

QA/QC approach Measurements were routinely controlled using the reference material built in the instrument. Certified reference materials (CRM) such as NCS DC78301 (river sediment, China National Analysis Center for Iron and Steel, Beijing, China), RM8407 (river sediment from Oak Ridge, Tennessee, NIST) and LGC6156 (harbour sediment, Setting standards in Analytical Science) were routinely used, mainly for consistency controls.

Replicate measurements were performed during control measurements in the laboratory after the field trip. The disparity in results is smaller when repeated shots are made without moving the instrument. This suggests that matrix heterogeneity is larger than measurement variability. In this regard, the multiplication of measurements at various points on a given sample significantly improves the reproducibility of the average measurements when compared to single measurements.

The evaluation of the analytical uncertainty of each measurement is based only on the uncertainty value reported by the spectrometer for each measurement (i.e. on counting statistics). This statistical uncertainty does not include matrix heterogeneity, to be evaluated with replicate measurements on the sample.

\section{RESULTS}

\section{Analysis of wet sludge}

Raw sediments with water contents of 60 to $70 \%$ were sampled by the CTP laboratories for treatment tests. Sludge samples were measured in their raw condition by $\mathrm{pXRF}$ and then progressively dried in a laboratory oven. Zinc, $\mathrm{Pb}, \mathrm{Cu}$ and As were the main pollutants detected by $\mathrm{pXRF}$. In Figure 4, 0\% refers to the raw sludge, $100 \%$ to the dried sample. Diamonds show results for various degrees of dehydration, while the error bars show the uncertainty calculated by the instrument for each measurement and the horizontal line indicates the LOD of each element.

Even if the water content of the sample is high (up to 60\%), the metal content in the sample can be measured and there is a linear relationship between this value and the water content (Figure 4). 


\section{Analysis of hand-pressed sediments}

During two field campaigns, samples were collected, partly dehydrated on-site by manual hand-pressing in tissue paper (Figure 2a) and then analysed on site (Figure $2 \mathrm{~b}$ ).

The water content reduction was efficient enough to improve the analytical conditions, but it was not possible to obtain the same water content in all samples. In order to determine more precisely the water content in the laboratory (Table 1), raw and pressed samples were kept in sealed bags during the second campaign.

Results by $\mathrm{pXRF}$ for $\mathrm{As}, \mathrm{Cu}, \mathrm{Zn}$ and $\mathrm{Pb}$ in wet and dried samples are shown in Figure 5, along with laboratory results by ICP-AES (aqua regia digestion). Arsenic is not reported for some samples because its content is close to or below the LOD $(8 \mathrm{mg} / \mathrm{kg})$ of pXRF. For the other elements $(\mathrm{Cu}, \mathrm{Zn}$ and $\mathrm{Pb})$, the first observations suggest that measured concentrations were roughly proportional to dry matter contents. Measurements on wet samples, corrected by a simple factor based on water content, are displayed together with them.

Despite large variations in measured concentrations for wet samples, the ranking of samples for each element is correctly displayed, and corrected measurements provide an acceptable approximation of the order of magnitude of the actual concentrations.

\section{Analysis of filter-pressed sediments on-site/after drying/after drying and crushing}

In order to test further the performance of pXRF on wet sediments, we tried to improve the efficiency of field dehydration. In the 2011 campaign, 85 samples were collected, dehydrated with a filter press device (Figure 3a and b) and then analysed on the boat with the XLt999KWY. Zn and Pb were the main pollutants detected by pXRF (Figure 6). Raw samples had water contents of between 35 and $58 \%$ before using the filter press device and between 24 and 38\% afterwards. As for manual hand-pressing, this method enabled the water content to be reduced in all samples by between 5 and $20 \%$. However, the range of humidity levels between samples is narrower with this method (14\% instead of $33 \%$ with manual hand-pressing).

Results for $\mathrm{Zn}$ and $\mathrm{Pb}$ obtained on-site by $\mathrm{pXRF}$ after filter-press dehydration are compared with results obtained later, after oven drying of the field pellets (Figure 6). This is aimed at evaluating the reliability of semi-wet data vs. data obtained on properly prepared samples.

Despite a high bias on absolute measurements, the linearity of the relationship between semi-wet and dry sample data is satisfactory enough to estimate absolute concentrations on field prepared samples.

\section{DISCUSSION}

As a general rule, it is assumed here that the most suitable sample preparation procedure to maximise $\mathrm{pXRF}$ performance is the same as traditional laboratory analysis: drying, milling to $200 \mu \mathrm{m}$ or less, sieving and splitting. The purpose of our study was to evaluate how far it is possible to depart from this procedure without sacrificing the representativeness of results.

\section{How much water is acceptable in samples to rank them with respect to a given element?}

Previous studies suggest that there is a roughly linear inverse relationship between water content and measured concentration. Should this relationship be really linear, it would be possible to calibrate a relationship between concentration and water content using standards and precisely measured water 
contents. Even a less precise relationship would nevertheless be useful, since it could enable samples to be ranked against the concentration of each element of concern.

In our results, such relationships are observed, even with values close to the LOD as for $\mathrm{Cu}$, but the regression slope varies between elements. It is possible to rank samples against their $\mathrm{Pb}, \mathrm{Zn}, \mathrm{Cu}$ or $\mathrm{As}$ contents with water contents of between $50 \%$ and $70 \%$.

\section{How much water is acceptable in samples to have a rough estimate of actual concentrations?}

Results from Figures 4 to 6 show that it is possible to estimate $\mathrm{Pb}, \mathrm{Zn}, \mathrm{Cu}$ or As dry concentrations from pXRF measurements on samples with water contents of between $25 \%$ and $50 \%$, without drying them.

The same issue is faced during soil remediation projects, where decisions have to be made regarding the destination of the excavated soil. The commonly accepted rule is that pXRF measurements made on soil with water contents up to $20 \%$ (Kalnicky \& Singhvi, 2001; US-EPA, 2007; Berger et al. 2009) or 30\% (Hürkamp et al. 2009) are still valid.

The moisture content affects the accuracy of the analysis, mainly through sample dilution. The measured concentration decreases as the water content increases, especially for elements with low energy Xray lines (less than $5 \mathrm{keV}$ ). This effect may however be counterbalanced by the reduced matrix absorption. The bias introduced by moisture is, therefore, dependent on the element and the matrix composition (Kalnicky \& Singhvi 2001). Our data suggest that measurements on samples with higher water contents (30 to $50 \%$ ) can still be used for decision-making, provided that they are obtained on similar matrices. Indeed, the absolute concentrations are severely affected, but in a roughly linear manner.

Correction factors were therefore calculated after measuring water contents in the laboratory (Table 1). These factors can be used to calculate corrected pXRF measurements for a given water content. Corrected measurements were found to be closer to pXRF measurements on dry samples, but also to results by ICPAES analysis (HF digestion). The best results were obtained with $\mathrm{Pb}$ and $\mathrm{Zn}$ (Table 2 and Figure 5).

This approach to account for water content for elements such as $\mathrm{Pb}, \mathrm{Zn}$ or $\mathrm{Cu}$ (to recalculate measurements on dry matter) has already been investigated for wet soil. For instance, a 1.51 factor was calculated by Hürkamp et al. (2009). However, the calculation of more precise regression coefficients shows that the correction factor is not the same for all elements (Table 2), even if it is directly correlated with the water contents.

An alternative approach to water correction would be calculating element ratios with a conservative element (for instance, Ti). This was attempted, but was not successful, due to the variation of ratios between elements of concern.

\section{How much water is acceptable in samples to recognise elemental signatures?}

In this case, despite differences between elements regarding their relation between concentration reading and water content, these differences usually do not mask the geochemical signature (Ho et al. 2012). Although the ranking of samples in terms of concentration remains correct, even with water contents $>50 \%$, the slope itself varies from element to element. However, the 'signature' elemental association is little affected: a sample with predominant $\mathrm{Cu}-\mathrm{Zn}$ will remain the same regardless of its concentration. Given this fact, the identification of a sediment as ' $\mathrm{Cu}-\mathrm{Zn}$ rich' and another one as ' $\mathrm{Pb}-\mathrm{Ag}$ rich' will be sound on the sole basis of $\mathrm{pXRF}$ results, even if the actual concentrations cannot be accurately given. 
As for many other applications, pXRF provides analytical results in relation to the level of sample preparation. However, laboratory-type sample preparation is too lengthy for decision-making analyses.

There is a relationship between pXRF measurements of metal contents and the water content of the sample. This relationship can be monitored during partial or total dehydration of the sample.

The measurements of metal contents in wet samples are correlated with metal contents in dry samples, even at high moisture levels (between 30 and $70 \%$ ). No convenient method is available to measure on-site the moisture level in sediments. The most efficient way to quickly dehydrate the sample is the filter-press: it provides less variability, even if the resulting moisture level remains high.

Elements are adequately detected and samples are correctly ranked according to their contents. Element signatures are well recognised. However, the filter-press system does not dehydrate sediments enough to achieve the $20 \%$ moisture threshold. The main objective for future developments would be to obtain a more or less constant moisture level, regardless of sediment texture, composition and initial water contents (e.g. $20 \%+/$ a few $\%)$.

The problems encountered with the water contents mainly affect the absolute accuracy of metal measurements, but they have little effect on the ranking of samples with a homogeneous composition and water content. In this regard, it is possible to build a site-specific scale of measurements with a robust relationship to the actual water contents.

Regardless of these analytical limitations, our work demonstrates that pXRF can be successfully used to evaluate the heavy metal and metalloid contamination of sediments, in a perspective of better spatial characterisation prior to dredging, of easier management during dredging works on waterways and for treatment. A proper estimation of analytical errors is required to evaluate the acceptable error risk in decision-making. This estimation is still site-dependent. Before using pXRF on wet samples for decision making, a preliminary study in laboratory conditions on similar material is still necessary.

\section{Acknowledgements}

The authors are grateful for the financial support of the European Union (ERDF InterReg IV program, GeDSeT project), the Public Service of Wallonia (DGO2 and DGO3), Voies Navigables de France (French Inland Waterways), the Nord Pas de Calais Regional Council and the French Ministry in charge of Research (BRGM research funding). They also thank Drs G.E.M. Hall and G. Bonham-Carter for their careful review and helpful suggestions, Niton Europe and Fondis Electronic France for fruitful discussions and support, and Dr Gregory Connelly for proofreading and revising the manuscript.

\section{References}

Berger, M., Zou L., \& Schleicher R., 2009. Analysis of Sulfur in the Copper Basin and Muddy River Sites. International Journal of Soil, Sediment and Water 2, 3, Article 1 (12-17-2009)

Bréquel, H., Iwaszko, A., \& Lucion, C., 2012. La plateforme expérimentale Solindus, Recyclage et Valorisation (Société de l'Industrie Minérale, Paris) 36, 60-65.

Cl:aire, 2008. Field Portable X-ray Fluorescence (PXRF): A rapid and low cost alternative for measuring metals and metalloids in soils. Research Bulletin 7, 4 p. Retrieved from www.claire.co.uk on April 2012. 
Crumbling, D. M., 2001. Using the Triad approach to improve the cost-effectiveness of hazardous waste site clean-ups. US-EPA report 542-R-01-016. Retrieved in 2001 from www.clu-in.org

Dalmacija, B., Prica, M., Ivancev-Tumbas, I., van der Kooij, A., Roncevic, S., Krcmar, D., Bikit, I., \& Teodorovic, I., 2006. Pollution of the Begej Canal sediment-metals, radioactivity and toxicity assessment. Environment International 32, 5, 606-615.

Higueras, P., Oyarzun, R., Iraizoz, J.M., Lorenz, S., Esbrí, J.M., \& Martínez-Coronado, A., 2012. Low-cost geochemical surveys for environmental studies in developing countries: Testing a field portable XRF instrument under quasi-realistic conditions. Journal of Geochemical Exploration, 113, 3-12.

Ho, H.H., Swennen, R., Cappuyns, V., Vassilieva, E., \& Tran, T.V., 2012. Necessity of normalization to aluminum to assess the contamination by heavy metals and arsenic in sediments near Haiphong Harbor, Vietnam. Journal of Asian Earth Sciences, In Press, Accepted Manuscript

Hürkamp, K., Raab, T., \& Völkel, J., 2009. Two and three-dimensional quantification of lead contamination in alluvial soils of a historic mining area using field portable X-ray fluorescence (PXRF) analysis.

Geomorphology, 110, 28-36.

Kalnicky, D.J., \& Singhvi, R., 2001. Field portable XRF analysis of environmental samples Journal of Hazardous Materials 83, 93-122

Kilbride, C., Poole, J., \& Hutchings, T.R., 2006. A comparison of $\mathrm{Cu}, \mathrm{Pb}, \mathrm{As}, \mathrm{Cd}, \mathrm{Zn}, \mathrm{Fe}, \mathrm{Ni}$ and $\mathrm{Mn}$ determined by acid extraction/ICP-OES and ex situ field portable X-ray fluorescence analyses. Environmental Pollution 143, 16-23

Kirtay, V.J., Kellum, J.H., \& Apitz, S.E., 1998. Field-portable X-ray Fluorescence Spectrometry for metals in marine sediments: Results from multiple sites. Water Science and Technology 37, 6-7, 141-148.

Laboudigue, A., Michel, P., Alary, C., Haouche, L., Lemière, B., Pereira, F., Hazebrouck, B., Hennebert, P., \& Lucion, C., 2011. The GeDSeT Project: coupling multi-criteria analysis and knowledge improvement on sediment for a close-to-the-field Decision Support Tool. 7th International SedNet conference, 6-9 April 2011, Venice, Italy.

Lemière, B., Michel, P., Jacob, J., Haouche, L., Laboudigue, A., 2012a. L'outil d'aide à la décision GeDSeT. Recyclage et Valorisation (Société de l'Industrie Minérale, Paris) 36, 52-58.

Lemière, B., Michel, P., Jacob, J., Haouche, L., Alary, C., Laboudigue, A., Brequel, H., \& Hazebrouck, B., 2012b. The GeDSeT project: constitution of a decision support tool (DST) for the management and material recovery of waterways sediments in Belgium and Northern France. WASCON, Göteborg, 30 May-1 June 2012. www.swedgeo.se/wascon2012

Martin, C.W., 2004. Heavy metal storage in near channel sediments of the Lahn River, Germany. Geomorphology, 61, 3-4, 275-285

Plater, A.J., Ridgway, J., Appleby, P.G., Berry, A., Wright, M.R, 1999. Historical Contaminant Fluxes in the Tees Estuary, UK: Geochemical, Magnetic and Radionuclide Evidence. Marine Pollution Bulletin, 37 (3-7), $343-360$

Robbat, Jr., A., 1997. Dynamic Workplans and Field Analytics: The Keys to Cost-effective Site Investigations, Tufts University, Case Study. 
Shefsky, S., 1995. Lead in Soil Analysis Using the NITON XL. International Symposium on Field Screening Methods for Hazardous Wastes and Toxic Chemicals (A\&WMA VIP-47), Las Vegas, Feb. 22-24, 1995, pp. 1106-1117.

US-DOE, 2001. Adaptive Sampling and Analysis Programs (ASAPs). Report DOE/EM-0592.

US-EPA (2007) Method 6200. Field portable X-ray fluorescence spectrometry for the determination of elemental concentrations in soil and sediment.

VanCott, R.J., McDonald, B.J., \& Seelos, A.G., 1999. Standard soil sample preparation error and comparison of portable XRF to laboratory AA analytical results. Nuclear Instruments and Methods in Physics Research A 422, 801-804 


\section{LIST OF ILLUSTRATIONS}

Figure 1: Canal sediment sampling by hand auger.

Figure 2: Sediment dehydration by hand and paper, and on-site analysis with the XLt999.

Figure 3: Sediment dehydration by manual filter press, a: the press tool, b: the part dehydrated sediment pellet.

Figure 4: $\mathrm{Pb}, \mathrm{Zn}$ and $\mathrm{Cu}$ measurements by pXRF (XLt999KWY model) on wet and dried sediments.

Figure 5: $\mathrm{As}, \mathrm{Cu}, \mathrm{Zn}$ and $\mathrm{Pb}$ measurements by pXRF (XL3t800 model) and ICP-AES on wet and dry sediments (the line indicates the LOD of each element).

Figure 6: $\mathrm{Zn}$ and $\mathrm{Pb}$ measurements by $\mathrm{pXRF}$ on wet and dry sediments prepared with the filter press device.

Table 1: Water content reduction through manual pressing.

Table 2: $\mathrm{Pb}, \mathrm{Zn}$ and $\mathrm{Cu}$ measurements of the wet, dry (ICP-AES) and recalculated measurements. 


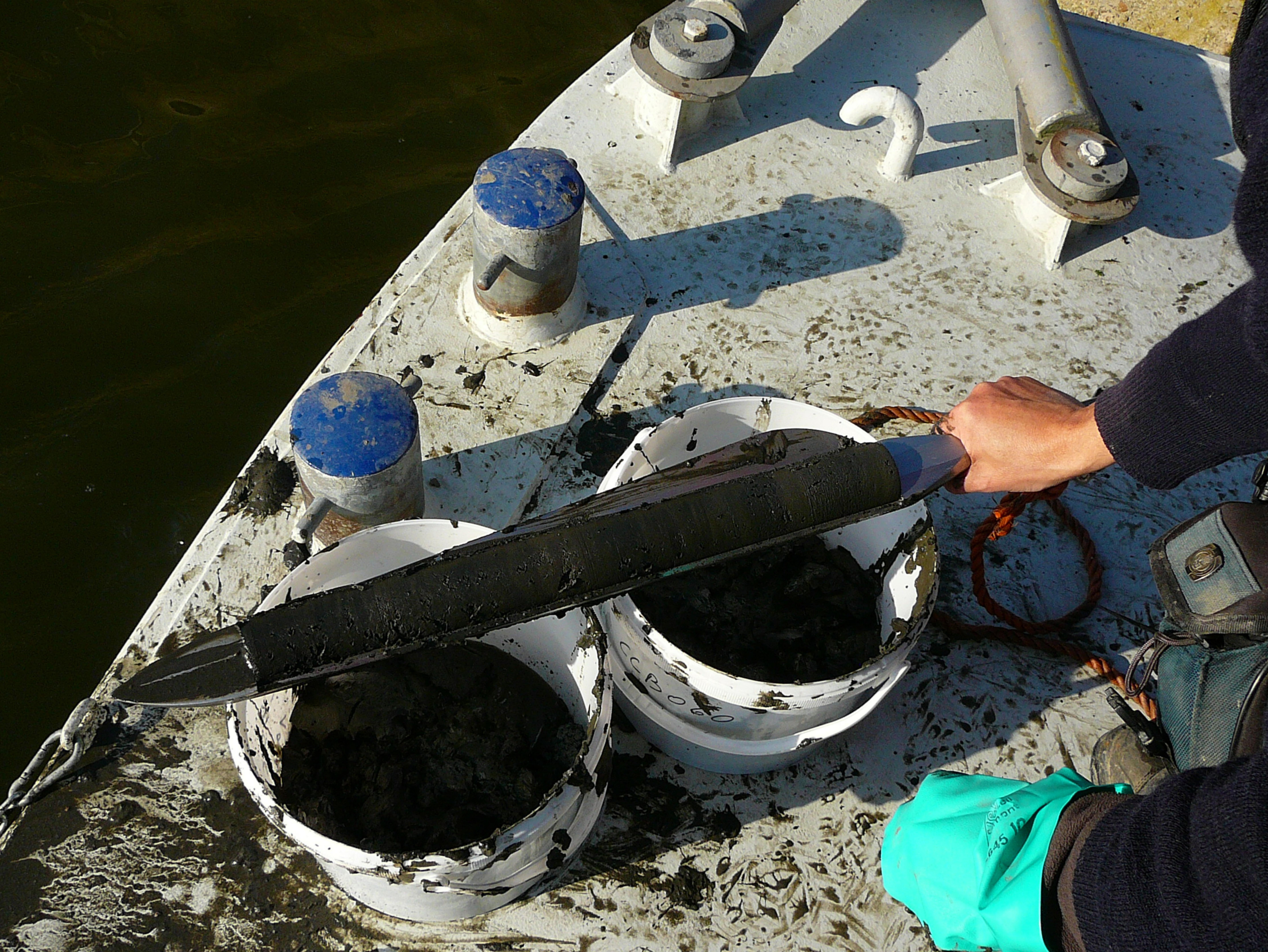




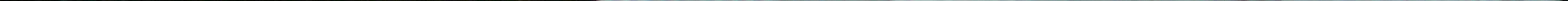




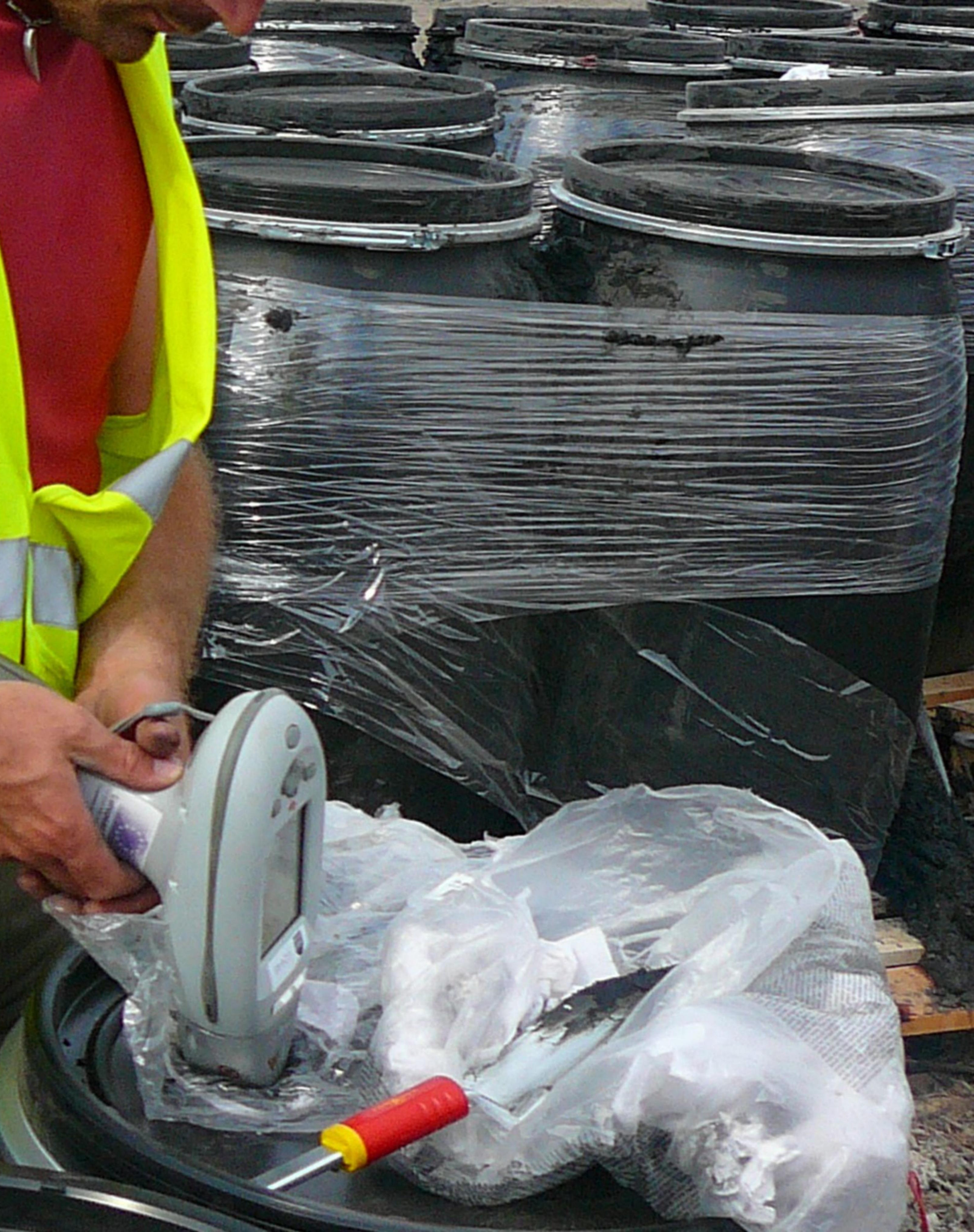




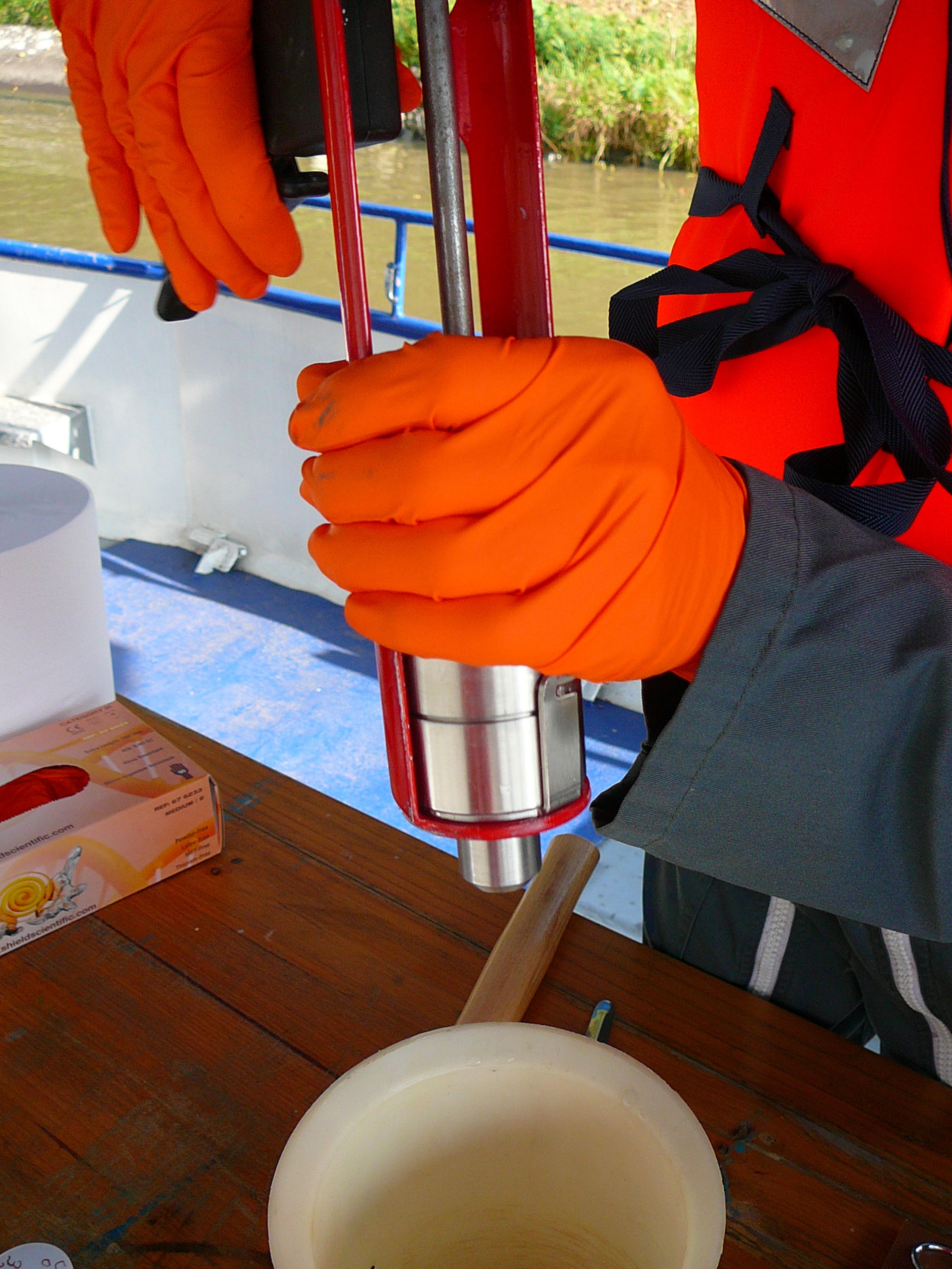




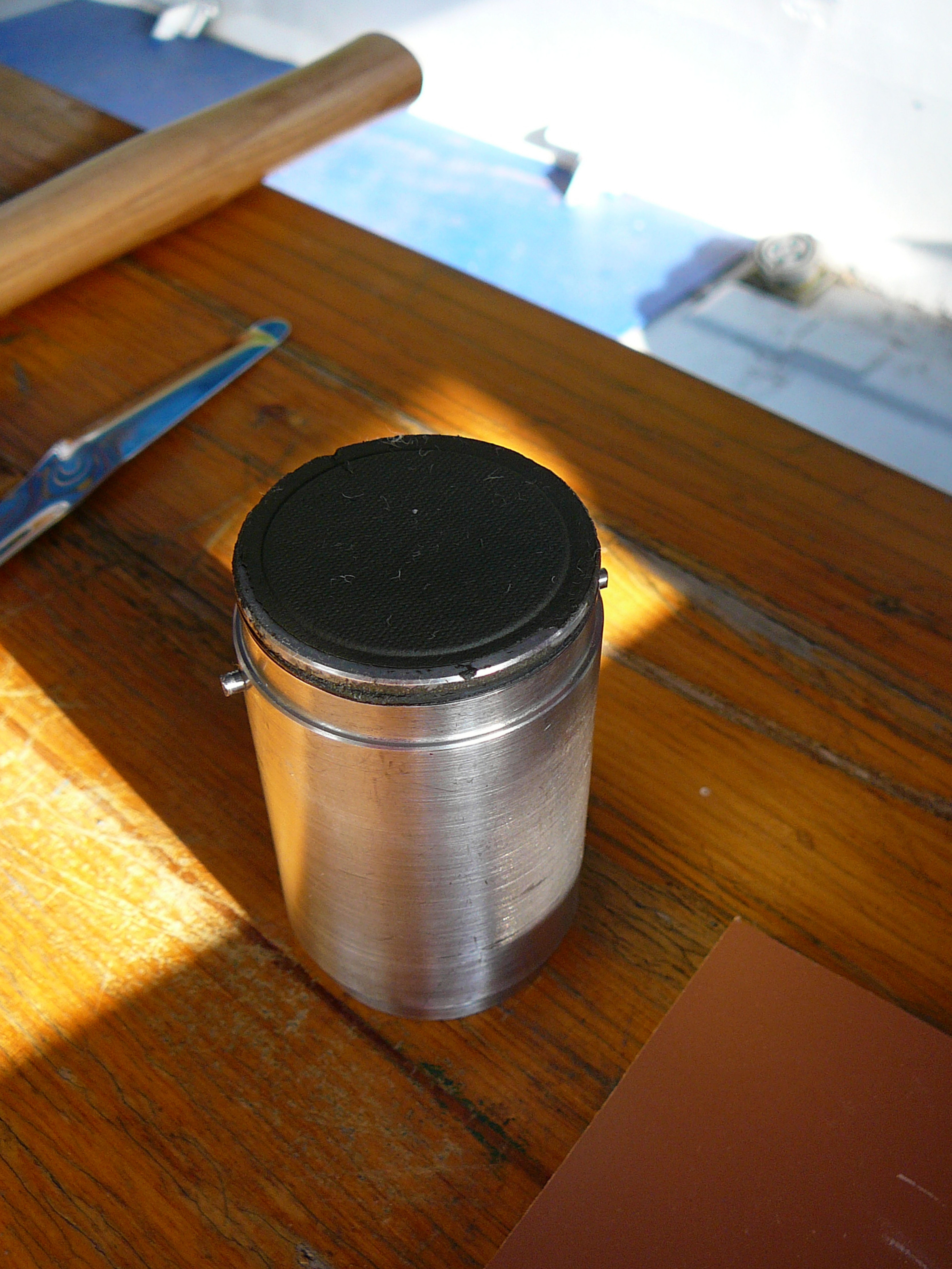




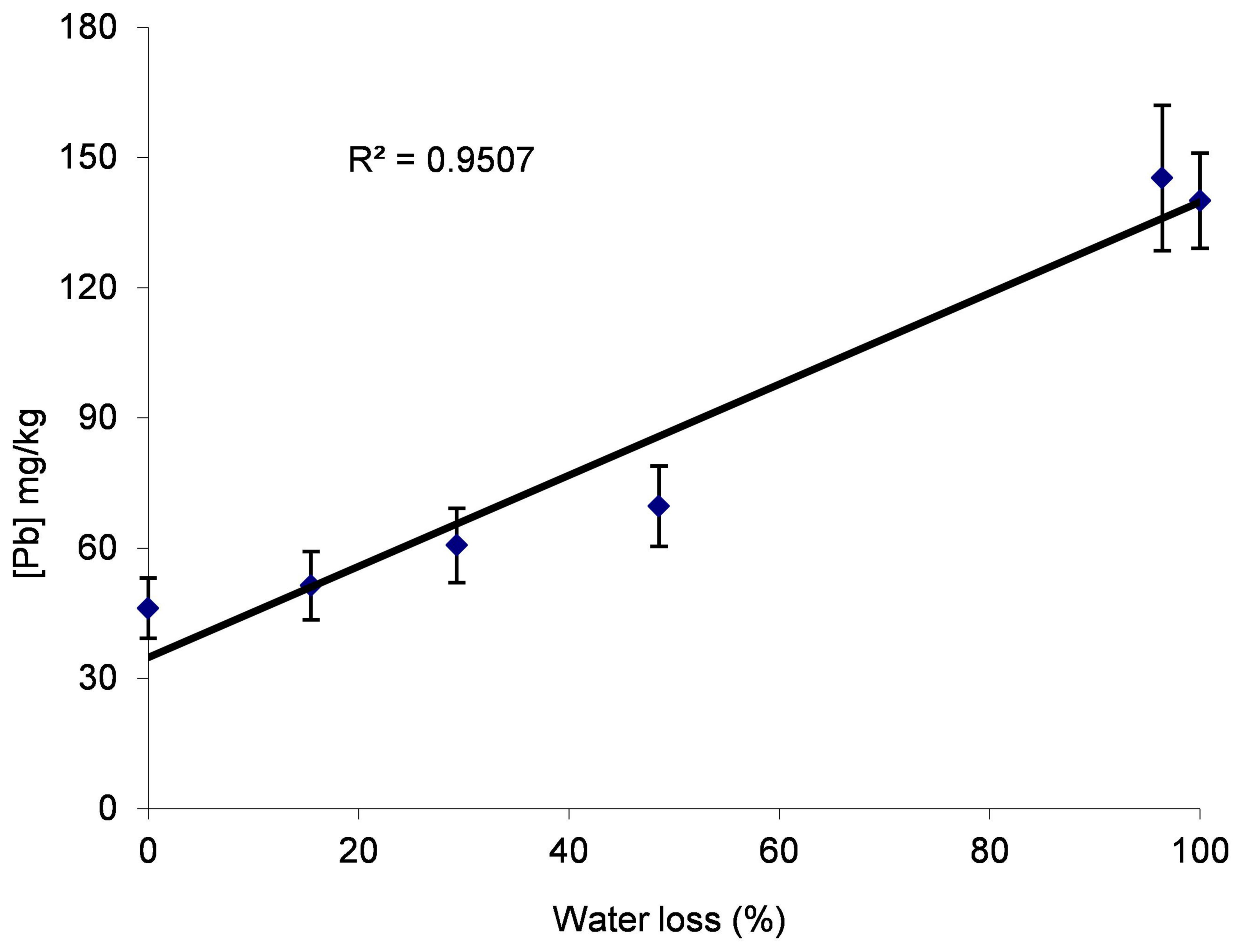




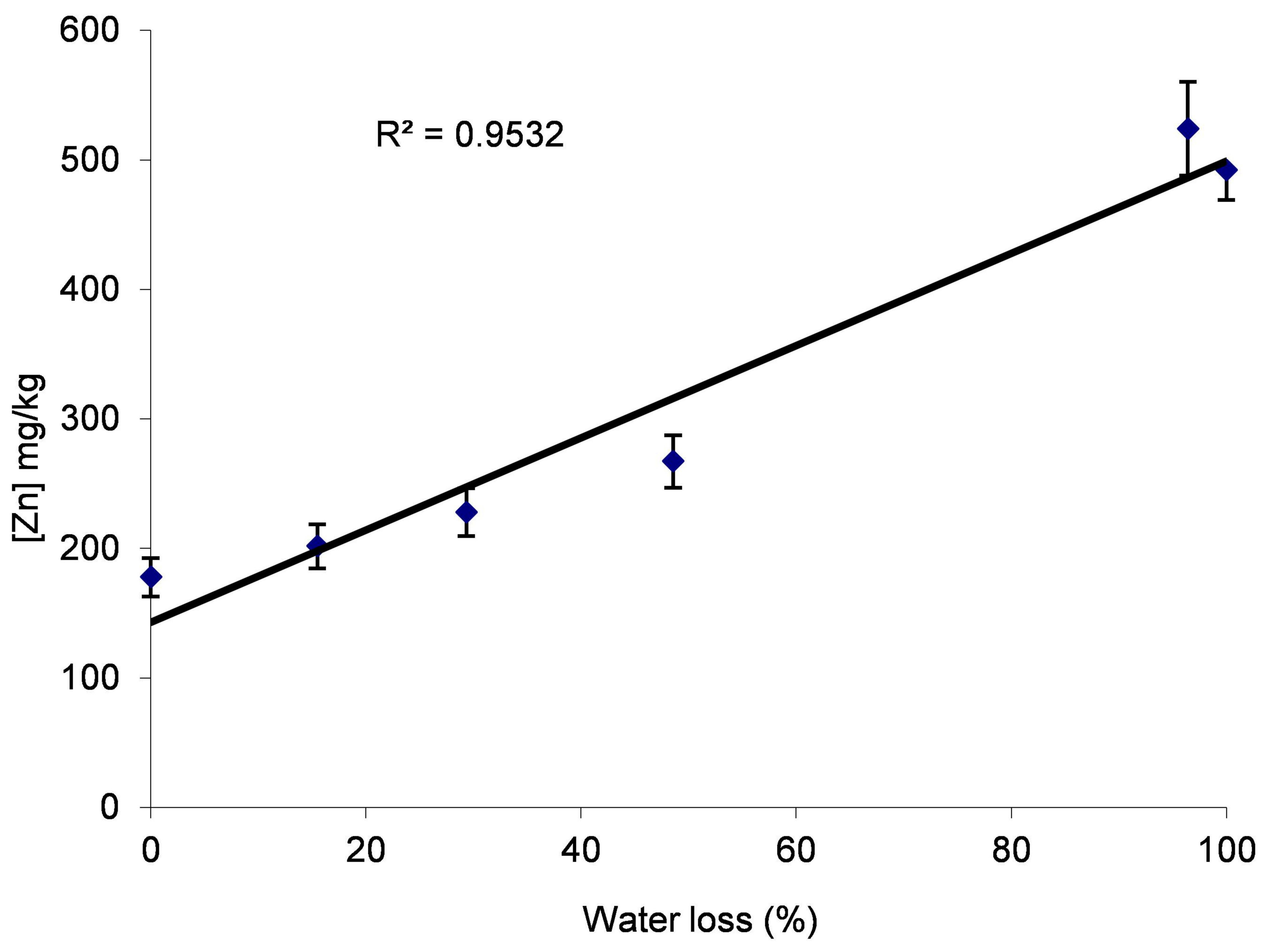




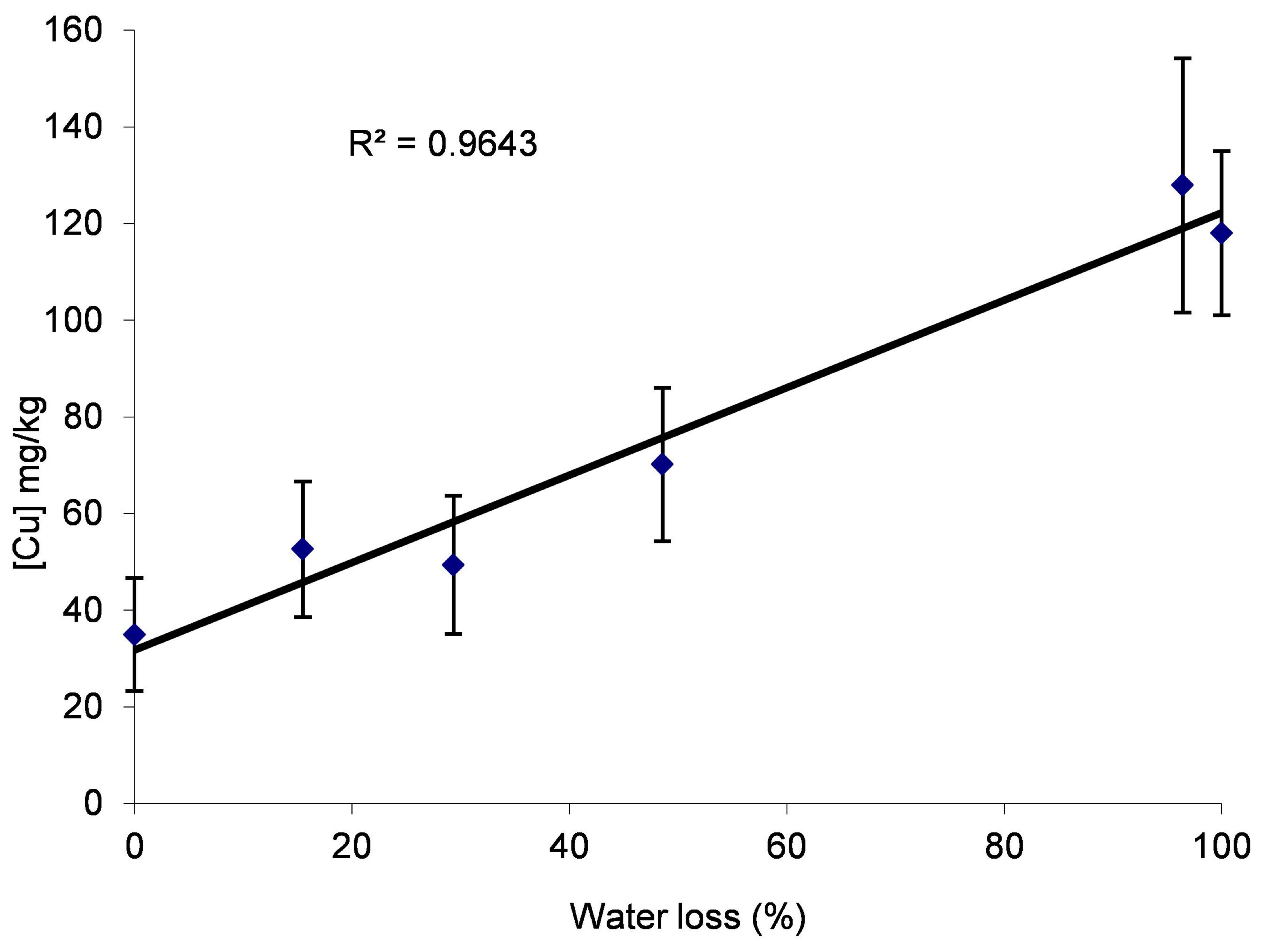









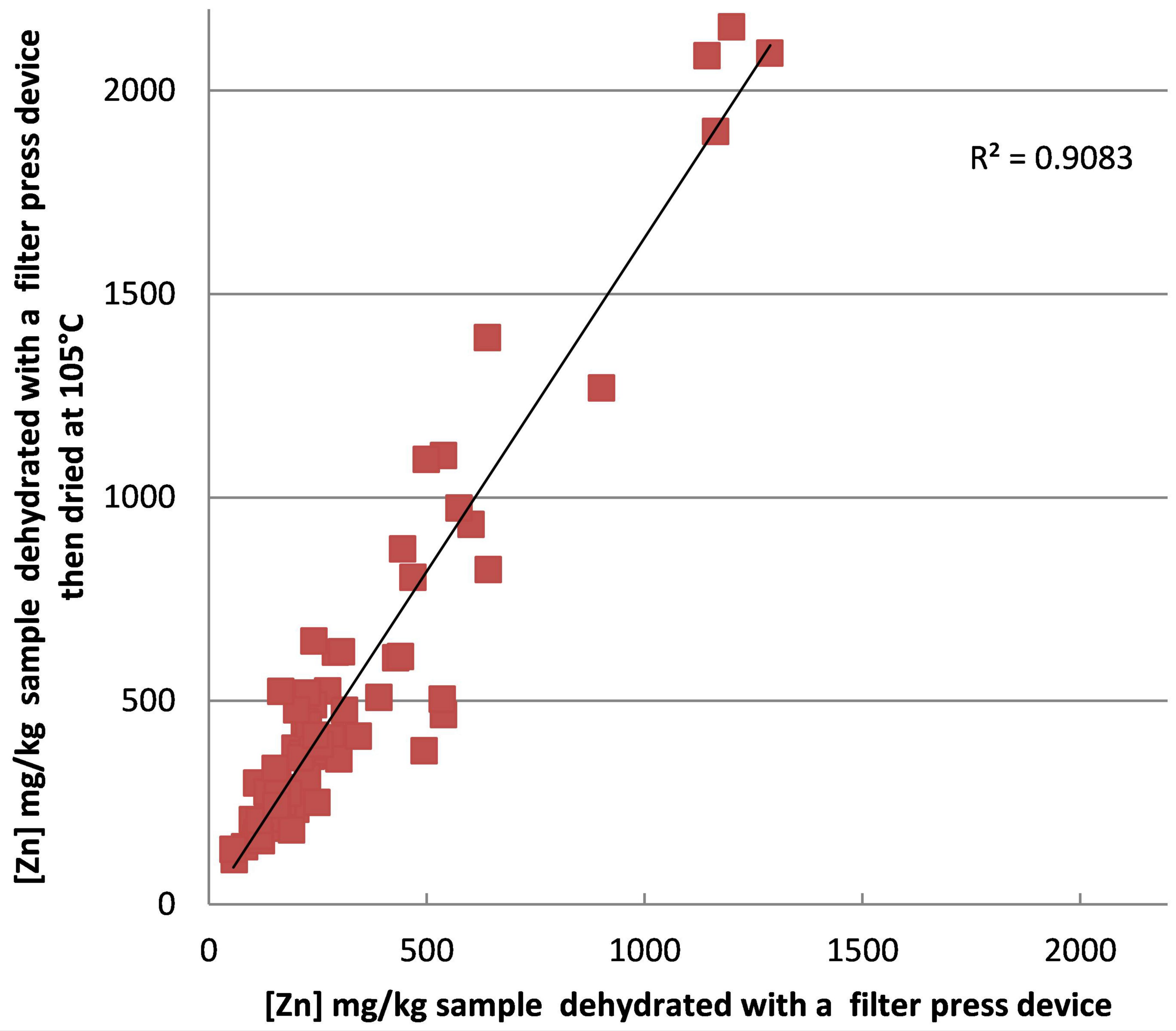




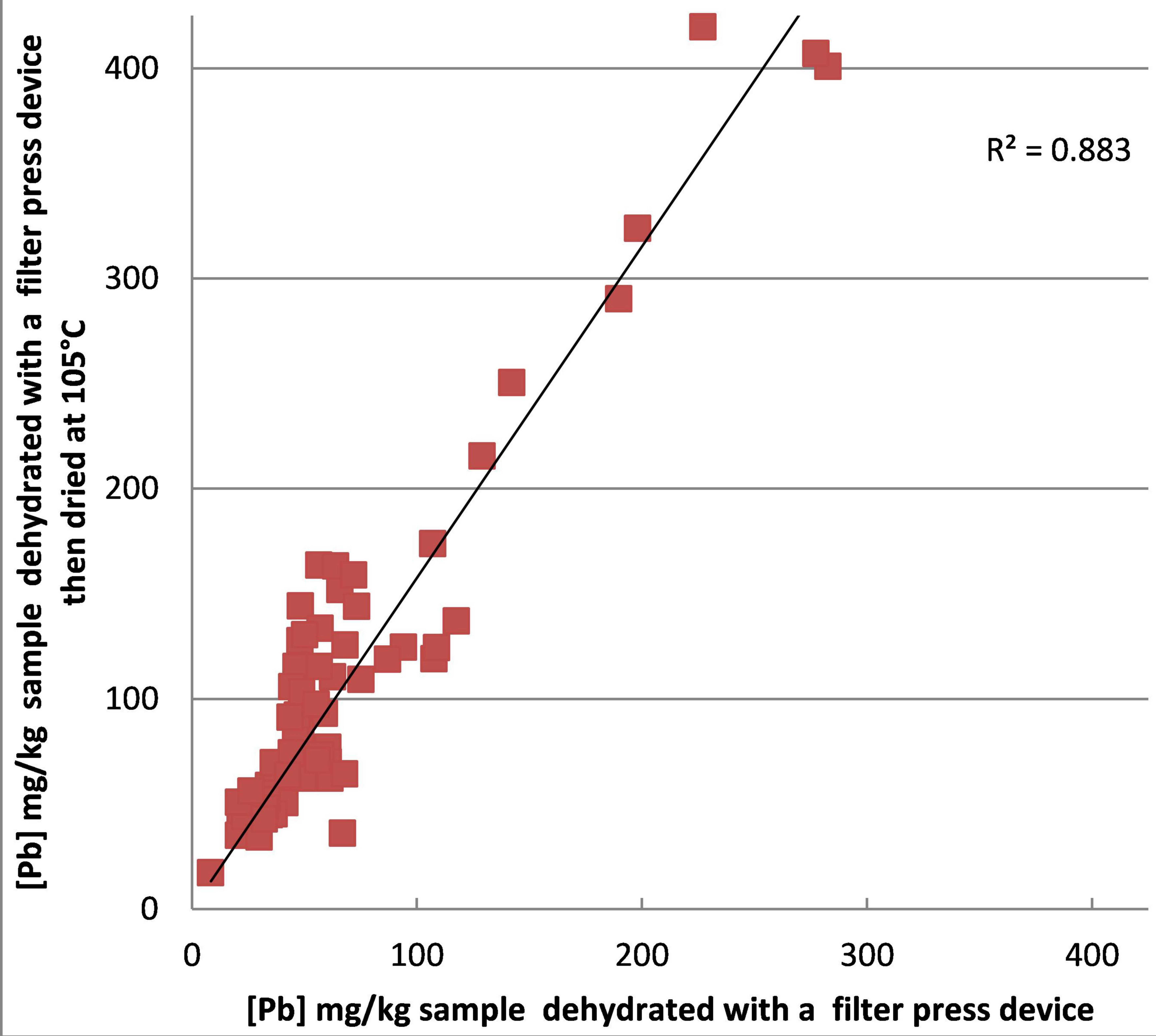




\begin{tabular}{|c|c|c|c|c|}
\hline Campaign & $\begin{array}{c}\text { Number of } \\
\text { samples }\end{array}$ & $\begin{array}{c}\text { Raw water } \\
\text { contents }\end{array}$ & $\begin{array}{c}\text { Water } \\
\text { content } \\
\text { after } \\
\text { manual }\end{array}$ & $\begin{array}{c}\text { Water } \\
\text { content } \\
\text { reduction }\end{array}$ \\
\hline 1 (sludge) & 17 & $\begin{array}{c}66.5- \\
74.1 \%\end{array}$ & $41.6-52 \%$ & $22-25 \%$ \\
\hline $\begin{array}{c}2 \\
\text { (sediments) }\end{array}$ & 13 & $40-65 \%$ & $26-49 \%$ & $11-18 \%$ \\
\hline
\end{tabular}




\begin{tabular}{|c|c|c|c|c|c|c|c|c|c|c|c|}
\hline $\begin{array}{l}\text { Drying } \\
\text { time } \\
\text { (hours) }\end{array}$ & $\begin{array}{c}\text { Moisture (M) } \\
(\%)\end{array}$ & $\begin{array}{c}\text { Moisture } \\
\text { factor } \\
100 /(100-\mathrm{M})\end{array}$ & $\begin{array}{c}{[\mathrm{Pb}]} \\
(\mathrm{mg} / \mathrm{kg})\end{array}$ & $\begin{array}{l}\text { Corr_Pb } \\
(m g / k g)\end{array}$ & $\begin{array}{c}\text { Corr_Pb } \\
\text { /ICP }\end{array}$ & $\begin{array}{c}{[\mathrm{Zn}]} \\
(\mathrm{mg} / \mathrm{kg})\end{array}$ & $\begin{array}{l}\text { Corr_Zn } \\
(\mathrm{mg} / \mathrm{kg})\end{array}$ & $\begin{array}{c}\text { Corr_Zn } \\
\text { /ICP }\end{array}$ & $\begin{array}{c}{[\mathrm{Cu}]} \\
(\mathrm{mg} / \mathrm{kg})\end{array}$ & $\begin{array}{l}\text { Corr_Cu } \\
(\mathrm{mg} / \mathrm{kg})\end{array}$ & $\begin{array}{c}\text { Corr_Cu } \\
\text { /ICP }\end{array}$ \\
\hline Sample A & $I C P-A E S$ & & 128 & & & 512 & & & 86 & & \\
\hline 0 & 61.9 & 2.63 & 46 & 121 & 0.95 & 178 & 467 & 0.91 & 35 & 92 & 1.07 \\
\hline 2 & 57.9 & 2.37 & 51 & 122 & 0.95 & 202 & 479 & 0.94 & 53 & 125 & 1.45 \\
\hline 4 & 53.5 & 2.15 & 61 & 130 & 1.02 & 228 & 490 & 0.96 & 49 & 106 & 1.23 \\
\hline 6 & 45.5 & 1.84 & 70 & 128 & 1.00 & 267 & 490 & 0.96 & 70 & 129 & 1.50 \\
\hline Sample B & $I C P-A E S$ & & 702 & & & 2836 & & & 77 & & \\
\hline 0 & 48.2 & 1.93 & 365 & 705 & 1.00 & 1284 & 2476 & 0.87 & 56 & 108 & 1.40 \\
\hline 2 & 43.5 & 1.77 & 413 & 730 & 1.04 & 1403 & 2482 & 0.88 & 64 & 112 & 1.46 \\
\hline 4 & 37.9 & 1.61 & 470 & 756 & 1.08 & 1645 & 2650 & 0.93 & 64 & 103 & 1.34 \\
\hline 6 & 30.5 & 1.44 & 523 & 752 & 1.07 & 1916 & 2755 & 0.97 & 83 & 120 & 1.56 \\
\hline Sample C & $I C P-A E S$ & & 178 & & & 1542 & & & 62 & & \\
\hline 0 & 49.7 & 1.99 & 84 & 166 & 0.93 & 639 & 1269 & 0.82 & 38 & 76 & 1.23 \\
\hline 2 & 36.7 & 1.58 & 114 & 181 & 1.01 & 864 & 1365 & 0.89 & 64 & 100 & 1.62 \\
\hline 4 & 28.4 & 1.40 & 129 & 180 & 1.01 & 966 & 1348 & 0.87 & 76 & 106 & 1.70 \\
\hline 6 & 18.0 & 1.22 & 152 & 186 & 1.04 & 1172 & 1430 & 0.93 & 82 & 100 & 1.61 \\
\hline 8 & 8.2 & 1.09 & 188 & 205 & 1.15 & 1312 & 1429 & 0.93 & 121 & 132 & 2.13 \\
\hline 10 & 4.3 & 1.04 & 191 & 200 & 1.12 & 1381 & 1442 & 0.94 & 106 & 111 & 1.79 \\
\hline
\end{tabular}

